\title{
A AUDIÊNCIA DE CUSTÓDIA E A BUSCA DOS DIREITOS HUMANITÁRIOS
}

Weslley Neponuceno de Paula, Pablo Rodrigo França

Universidade do Oeste Paulista - UNOESTE, curso de Direito, Presidente Prudente, SP. E-mail: weslleyneponuceno@gmail.com

\section{RESUMO}

Diante do atual panorama carcerário brasileiro surgem diversos rumores e implantações de projetos e instrumentos, sempre visando à sua redução. Em meio a essa problemática, com fundamento garantista e preocupado com a desumanidade do atual sistema prisional, frente aos crimes de menor lesividade ou até mesmo a presunção de não culpabilidade, mas, encarando celeumas e tempestades de críticas, surge à audiência de custódia. Entre o debate de sua consagração e os argumentos lançados, muitas vezes frágeis e distorcidos, ou a menos prefixados a favor do encarceramento em massa, o valor da audiência de custódia se exalta, com resultados que não conduziram a percepção da impunidade ou aumento da reincidência, contudo, afastou da segregação boa parte da comunidade já aprisionada pelo preconceito social, em homenagem aos direitos humanitários, fundamentais, tão propagados pelos pactos internacionais e ratificados por esta nação.

PALAVRAS CHAVES: Custódia. Encarceramento. Audiência. Prisões. Redução.

\section{THE AUDIT OF CUSTODY AND THE SEARCH FOR HUMANITARIAN RIGHTS}

\begin{abstract}
In the face of the current Brazilian prison situation, there are several rumors and projects and instruments, always aimed at reducing prisons. In the midst of this problem, with a conviction and concern about the inhumanity of the current prison system, in the face of crimes of lesser harm or even presumption of non-culpability, but, facing clutter and storm of criticism, appears to the custody hearing. Between the debate of its consecration and the arguments that were launched, often fragile and distorted, or less prefixed in favor of mass incarceration, the value of the custody audience is exalted, with results that did not lead to the perception of impunity or increase in recidivism, However, removed from the segregation a good part of the community already imprisoned by social prejudice, in honor of the fundamental humanitarian rights, so propagated by the international pacts and ratified by this nation.
\end{abstract}

KEYWORDS: Custody. Incarceration. Audience. Prisons. Reduction

\section{INTRODUÇÃO}

O presente artigo diz respeito a um instrumento que há muito tempo se faz presente em solo brasileiro, porém, só agora veio a ser alvo de debates e efetiva implantação: a audiência de custódia.

O instituto, em breve análise, sempre esteve presente por meio de tratados e convenções internacionais, traduzindo na prática e de maneira básica a determinação em apresentar a pessoa que se encontra em estado de flagrância imediatamente ao encontro do magistrado competente, logo após a formalização da prisão, para que este avalie a real necessidade ou não da sua manutenção segregada da sociedade.

Nada obstante ao resultado prático à persecução, mais importante, é a primazia na proteção aos direitos humanitários daqueles que se encontram na iminência de agregar a 
comunidade excluída do convívio social, notadamente na transição no que diz respeito a possibilidade de sofrimento de tortura ou maus-tratos nas unidades prisionais.

$\mathrm{O}$ estudo não pautou em planilhar a quantidade ou determinar vantagens no prender mais ou menos, e sim em adequar o instituto a realidade hodierna, afastando incoerências ou manutenção de prisões desnecessárias que, em verdade, além de trilhar caminhos sem resquício de humanidade (ao detento) acabava por incutir a desesperança na justiça pública e órgãos constituídos onde, a pequeno e médio prazo, transforma-o em delinquente profissional, em típico resultado inverso a ressocialização.

Assim, o presente trabalho é de importância inconteste, com o objetivo de forçar um melhor estudo da medida com discussões acadêmicas sem o preconceito equivocado, possibilitando novos entendimentos e questionamentos, aproveitando a análise para o aperfeiçoamento do sistema ou modelo, em homenagem a paz pública, segurança e aos clamados direitos humanitários.

\section{METODOLOGIA}

Este ensaio foi desenvolvido por análises e pesquisas de obras bibliográficas, jurisprudências e artigos científicos, inclusive eletrônicos, aproveitando de estudos realizados academicamente, aplicando como método principal, sem afastamento de outros, ao hipotéticodedutivo.

Houve a tentativa de aflorar sobre o instituto da audiência de custódia, descrevendo os paradigmas e propondo a quebra de conceitos preestabelecidos que apenas busca a manutenção de básicos direitos fundamentais, partindo do raciocínio lógico amplo para o restrito, em confronto dialético.

\section{RESULTADOS}

$\mathrm{Na}$ atualidade, em muitos momentos através da imprensa e, especialmente, na doutrina se discute a crise do sistema carcerário onde pouco se preocupa com o ser humano ali segregado, onde a sociedade exalta a massificação das prisões, sem perceber que aqueles mesmos indivíduos tratados como bichos um dia terminam a sua pena e retornam ao convício coletivo, com a régua do caráter alterado para o mal. Isso explica os tantos baixos índices de ressocialização.

Neste diapasão, considerando as condições carcerárias expostas, ainda, o negativo resultado das segregações, especialmente aos casos de menor lesividade ou que não denotam profissionalismo infrator, surgiu à efetivação da audiência de custódia no Brasil que paulatinamente vem sendo implantada em todos os Estados e cidades da Federação.

Conforme bem definido na doutrina sobre a audiência de custódia:

$\mathrm{O}$ ato jurídico popularmente conhecido como audiência de custódia consiste na condução do preso, sem demora, à presença de uma autoridade judicial que deverá, após a realização de um contraditório entre acusação e defesa, exercer um controle imediato da legalidade e da necessidade da prisão, além de verificar questões relativas à pessoa do conduzido, em relação a maus-tratos e tortura. (ANDRADE; ALFLEN, 2016, p. 15).

Empiricamente, o resultado tem sido a liberação imediata de quase metade dos presos em flagrante, não por atuação equivocada das polícias, mas, pela real desnecessidade, segundo julgamento judicial, na manutenção daqueles indivíduos segregados, em face de pequenas lesões aos bens jurídicos ou ausência de gravidade nas ações perante a sociedade, o que também 
ameniza a problemática da superpopulação carcerária, o que possivelmente apenas se consumaria com a atuação ativa de um defensor ou na primeira audiência judicial que, a depender da realidade local, durariam meses. O resultado é a vitória da cidadania e da humanidade.

\section{DISCUSSÃO}

Segundo Mauro Fonseca Andrade e Pablo Rodrigo Alflen, os resquícios sob o surgimento, bem como a necessidade da audiência de custódia, sobretudo, um direito de defesa e respeito aos direitos humanos, partiu de inúmeros debates:

O Conselho da Europa, a partir dos ditames presentes na Declaração Universal dos Direitos Humanos, criou a Convenção Europeia para a Proteção dos Direitos Humanos e Liberdades (CEDH), em 04 de novembro de 1950, estabelecendo a necessidade da condução sem demora de toda pessoa detida ou presa à presença de um juiz ou outra autoridade habilitada para desempenhar tais funções. (ANDRADE; ALFLEN, 2016, p. 13).

Como se não bastasse, em 22 de novembro de 1969, em San José da Costa Rica, delegados dos Estados-Membros da Organização dos Estados Americanos, em uma Conferência Especializada Interamericana sobre Direitos Humanos, aprovou-se então a chamada Convenção Americana sobre Direitos Humanos (CADH). Porém, sua vigência só veio à tona no dia 18 de julho de 1978, e ratificada em solo brasileiro pelo Decreto $n^{\circ} 678$, de 09 de julho de 1992, reproduzindo a ideia de apresentação imediata da pessoa em situação de flagrante direta ao magistrado ou qualquer outra autoridade que esteja apta para tal procedimento. Reprodução essa que ficou conhecida no Brasil como audiência de custódia (ANDRADE; ALFLEN, 2016, p. 13 e 14).

No que se refere à previsão normativa quanto à aplicabilidade da audiência, encontra-se fundamento em vários dispositivos internacionais de direitos humanos. O primeiro deles, e talvez o mais conhecido em âmbito jurídico, é o próprio e precitado Pacto de San José da Costa Rica, ou mais conhecido como Convenção Americana de Direitos Humanos (CADH). Destaca-se o seu artigo 7, item 5:

Toda pessoa presa, detida e retida deve ser conduzida, sem demora à presença de um juiz ou outra autoridade autorizada por lei a exercer funções judiciais e tem o direito de ser julgada em um prazo razoável ou de ser posta em liberdade, sem prejuízo de que prossiga o processo. Sua liberdade pode ser condicionada a garantias que assegurem o seu comparecimento em juízo. (PACTO DE SAN JOSÉ DA COSTA RICA, 1992).

Outro dispositivo que fundamenta a questão da audiência de custódia por meio de tratados internacionais no Brasil é o artigo $9^{\circ}$, tópico $3^{\circ}$, do Pacto Internacional de Direitos Civis e Políticos de Nova lorque:

Qualquer pessoa presa ou encarcerada em virtude de infração penal deverá ser conduzida, sem demora, à presença do juiz ou de outra autoridade habilitada por lei a exercer funções judiciais e terá o direito de ser julgada em prazo razoável ou de ser posta em liberdade. A prisão preventiva de pessoas que aguardam julgamento não deverá constituir a regra geral, mas a soltura a poderá estar condicionada a garantias que assegurem o comparecimento da pessoa em questão à audiência, a todos os atos do processo e, se necessário for, para a execução da sentença. 
(PACTO INTERNACIONAL SOBRE DIREITOS CIVIS E POLÍTICOS DE NOVA IORQUE, 1992).

Por fim, neste trabalho resumido, citamos a Convenção Europeia de Direitos Humanos (CEDH), em seu artigo $5^{\circ}$, item $3^{\circ}$ :

Qualquer pessoa presa ou detida nas condições previstas no parágrafo 1 , alínea c), do presente artigo deve ser apresentada imediatamente a um juiz ou outro magistrado habilitado pela lei para exercer funções judiciais e tem direito a ser julgada num prazo razoável, ou posta em liberdade durante o processo. A colocação em liberdade pode estar condicionada a uma garantia que assegure a comparência do interessado em juízo. (CONVENÇÃO EUROPEIA DE DIREITOS HUMANOS, 1950).

Muito embora signatário de tais convenções e pactos internacionais de direitos humanos civis e políticos que estipulam esta apresentação do preso de imediato frente ao juiz, no Brasil, até a presente data, não possui expressamente no ordenamento jurídico dispositivo que regulamenta a aplicação da audiência de custódia. Porém, apenas alguns resquícios no artigo 306 do Código de Processo Penal, se tratando não da apresentação da pessoa detida à presença do juiz ou autoridade competente, mas sim o auto de prisão em flagrante.

Sob esse aspecto, fica evidente que o Brasil, encontra-se em uma situação paradoxal no que concerne à aplicação da audiência de custódia em seu regime, pois, mesmo depois de 23 anos de ratificar a Convenção Americana de Direitos Humanos, ainda caminha lentamente para que o sujeito preso tenha rápido contato com uma autoridade judicial competente para verificar a necessidade real da segregação (ANDRADE; ALFLEN, 2016, p. 14).

A audiência de custódia pode ser entendida como a tentativa mais ambiciosa de tentar frear o grande encarceramento em massa de prisões precoces, desnecessárias, arbitrárias e ilegais, bem como afastar qualquer possibilidade de abusos ou atos de tortura, violência, sob aquele que está em condição de detido.

Repita-se que não se trata em aferir sobre prender mais ou prender menos, e sim, evitar prisões, ou melhor, encarceramentos de pessoas que melhor seriam readaptadas em liberdade, respondendo ao processo sem o risco em transformá-lo em subproduto das carceragens mal condizentes brasileiras.

A audiência de custódia efetivamente tem o objetivo em consolidar direitos humanos consagrados que dão base ao mínimo existencial.

No Brasil, a prática da audiência suprarreferida exige que o preso em flagrante seja em no máximo 24 horas encaminhado diretamente ao juiz competente para que análise a eventual necessidade de recolhimento ao sistema carcerário, ou o seu relaxamento.

O Conselho Nacional de Justiça também se manifestou a respeito da audiência de custódia, afirmando que:

Trata-se de uma ação do Conselho Nacional de Justiça mediante a qual o cidadão preso em flagrante é levado à presença de um juiz no prazo de 24 horas. Acompanhado de seu advogado ou de um defensor público, o autuado será ouvido, previamente, por um juiz, que decidirá sobre o relaxamento de prisão preventiva. O juiz também avaliará se a prisão preventiva pode ser substituída por liberdade provisória até o julgamento definitivo do processo, e adotará, se for o caso, medidas cautelares como monitoramento eletrônico e apresentação periódica em juízo. Poderá determinar, ainda, a realização de exames médicos para apurar se houve 
maus-tratos ou abuso policial durante a execução do ato de prisão. (CNJ, 2016, p. 5).

Conforme descrito no presente ensaio, muito além de optar pela liberdade da pessoa detida, assumindo como premissa fundamental e necessária à presunção de inocência, a audiência de custódia deve garantir que a prisão cautelar não seja concretizada com a intenção de antecipar uma possível pena e devendo ser usada somente "quando não for cabível a substituição por outra medida cautelar diversa", art. 282, §6², Código de Processo Penal (BALLESTEROS, 2016, p. 22).

Leciona Luiz Flávio Gomes:

A audiência de custódia representa a civilização (e a racionalidade). Quem a combate (ou cria empecilhos para ela) são as almas impregnadas de inquisitorialismo, de torquemadismo, de autoritarismo patriarcal. Constitui um erro desprezar esses torquemadas remanescentes da Idade Média: eles existem.

O trabalho, conforme facilmente percebido, ciente do discurso sem embasamento e fragilizado de ideias preconcebidas e sem nenhuma base científica, em verdade, clama pela atenção e discussão do assunto ainda pouco conhecido e que tem como simples pano de fundo o garantismo de um dos direitos humanitários básicos a sobrevivência digna.

\section{CONCLUSÃO}

É alarmante e também intrigante como um direito fundamental pode ter sido há tanto tempo esquecido e deixado para trás como o instituto da audiência de custódia no Brasil. Hoje, o fruto de seu uso é inegável, mesmo com eventuais resquícios a margem de um olhar torto social e outras dificuldades a serem sanadas como qualquer instrumento em começo de implantação.

Porém, é uma realidade que naturalmente encara a tempestade de críticas e preconceitos. O seu valor, sem dúvidas, se mostrará quando almas errantes pararem de se prender a conceitos há muito ultrapassado, deixando de sucumbir à pressão frente ao assustador cenário carcerário.

Que os holofotes sejam direcionados aos gritos ecoados daqueles que encontram em situações desumanas nos ergástulos brasileiros.

\section{REFERÊNCIAS BIBLIOGRÁFICAS}

ANDRADE, Mauro Fonseca, ALFLEN, Pablo Rodrigo, Audiência de Custódia: da boa intenção à boa técnica, Edição Única, Porto Alegre, FMP - Fundação Escola Superior do Ministério Público, 2016.

BALLESTEROS, Paula R. Implementação das audiências de custódia no Brasil: análise de experiências e recomendações de aprimoramento. Edição única. Brasília. PNUD - Ministério da Justiça e Departamento Penitenciário Nacional, 2016.

BRASIL. Código de Processo Penal. Decreto Lei no 3689, de 3 de Outubro de 1941. Disponível em: http://www.planalto.gov.br/ccivil_03/decreto-lei/Del3689.htm Acesso em 6 de jun.2017.

BRASIL. Pacto Internacional sobre Direitos Civis e Políticos (1992). Disponível em: >http://www.planalto.gov.br/ccivil 03/decreto/1990-1994/D0592.htm Acesso em: 20 de jun.2017.

CEDH. Convenção Europeia de Direitos Humanos. (1950). Disponível em: >http://www.echr.coe.int/Documents/Convention POR.pdf Acesso em: 20 jun.2017. 
CNJ, Conselho Nacional de Justiça, Audiência de Custódia, Edição Única, Brasília, CNJ, 2016.

Organização dos Estados Americanos, Convenção Americana de Direitos Humanos (Pacto de San José da Costa Rica), 1969. Disponível em: < http://www.planalto.gov.br/ccivil_03/decreto/d0678.htm Acesso em: 16 de abr.2017.

GOMES, Luiz Flavio, Audiência de Custódia e a resistência das almas inquisitoriais. Disponível em: <http://institutoavantebrasil.com.br/audiencia-de-custodia-e-a-resistencia-das-almasinquisitoriais/ Acesso em: 01 de ago.2017. 